\section{Takayasu's arteritis}

Takayasu was a Japanese ophthalmologist who in 1908 published a report of a curious fundal appearance in a 21-year-old woman. ' When he presented the problem at a conference of the Japanese Ophthalmological Society a colleague contributed another patient with similar ocular appearances combined with a remarkable absence of pulses in the arms. So began the story of Takayasu's arteritis or aortitis, a syndrome described under 15 or more names in contributions from all over the world. The term pulseless disease was suggested in Tokyo in 1951 by Shimizu and Sano, ${ }^{2}$ who also emphasised the ocular and cerebral aspects of the condition. Though the bulk of cases have been reported from Japan the condition is not confined to the Orient or to any ethnic group. Reports from Britain have been sparse ${ }^{3-5}$ but include two 19th-century descriptions. ${ }^{6} 7$

From the many accounts $\mathrm{s}^{8-14}$ there emerges an entity distinct from other processes affecting the aorta and major arteries, such as atheroma, syphilis, medionecrosis, or giant cell arteritis. The disease classically affects young women aged between 10 and 30 , the sex ratio being at least 7 to 1 . The pathological process is a panarteritis, ${ }^{15}$ probably first affecting the adventitia and vasa vasorum and leading to secondary changes in the media, where the most characteristic finding is loss of elastic tissue. The intima responds by proliferation with subsequent thrombosis, the end result being stenosis, occlusion, or aneurysm formation. In its most familiar form the aortic arch and the big trunks arising from it are affected, but lesions are common in the descending thoracic and abdominal aorta, and most if not all reports of "congenital coarctation" at atypical sites are probably examples of the condition. ${ }^{16}$ The pulmonary artery may also be affected, with an incidence of $45^{\circ}$, in 76 necropsies reported from Japan. ${ }^{14}$

The disease starts as an acute or subacute systemic illness, the features of which mimic countless other conditions and include fever, sweating, fatigue, cough, haemoptysis, pleurisy with effusion, arthralgia, abdominal pain, anaemia, raised sedimentation rate, and abnormal plasma proteins. The most specific findings are tenderness of the main arterial trunks and the development of bruits. The systemic features, often undramatic or unrecognised, may merge with those arising from arterial stenosis or occlusion, which dominate the later stages of the disease, or there may be a latent interval of weeks or months before ischaemic manifestations appear. The modes of presentation of this established phase depend on the location of the arterial lesions, the commonest being absence of the upper limb pulses and manifestations (sometimes bizarre) of cerebral, ocular, or facial ischaemia. Hypertension from renal artery stenosis, ${ }^{15}$ cardiac failure, coronary thrombosis, and aortic incompetence ${ }^{11}$ are other complications. The condition has rightly been termed" another "great imitator," which may land the sufferer in almost any hospital department. The diagnosis is confirmed radiologically. Lande et alli have emphasised the importance of visualising the whole aorta, including the origins of all its branches in both thorax and abdomen, if the extent of the disease is to be discovered.

The aetiology remains obscure. The coincidence of pulseless disease with conditions such as tuberculosis ${ }^{10} 18$ has been noted, but the current consensus favours a hypersensitivity or autoimmune reaction. No succinct statement on prognosis is possible. The disease may progress rapidly with death from complications within a few months, or the process may burn out, leaving the patient many years of life with symptoms from whatever vascular damage was done. Anticoagulant therapy ${ }^{12}$ has been used, though without striking benefit, and it is not compatible with the more favoured steroid treatment-from which (while information is scanty) symptomatic improvement and even return of absent pulses have been reported. ${ }^{12} 13$ Immunosuppressive drugs ${ }^{19}$ may prove of value, but more experience is needed. Surgical relief may be possible for established vascular occlusions or stenoses. ${ }^{20} 21$

1 Takayasu, M, Acta Societatis Ophthalmologicae faponicae, 1908, 12, 554. 2 Shimizu, K, and Sano, K, Fournal of Neuropathology and Clinical Neur$\operatorname{olog} y, 1951,1,37$.

${ }^{3}$ Lewis, T, and Stokes, J, British Heart fournal, 1942, 4, 57.

4 Skipper, E, and Flint, F J, British Medical fournal, 1952, 2, 9.

5 Strachan, R W, Quarterly fournal of Medicine, 1964, 33, 57.

' Savory, W S, Medical and Chirurgical Transactions of London, 1856, 39, 205.

'Broadbent, W H, Transactions of the Clinical Society of London, 1875, 8,

8 Ross, R S, and McKusick, V A, Archives of Internal Medicine, 1953, 92, 701 .

${ }^{9}$ Bonventre, M V, New' York State Fournal of Medicine, 1974, 74, 1960.

10 Sen, P K, et al, British Heart fournal, 1963, 25, 610.

1 Schrire, V, and Asherson, R A, Quarterly fournal of Medicine, 1964, 33, 439.

12 Nakao, K, et al, Circulation, 1967, 35, 1141.

${ }_{13}$ Fraga, A, et al, Arthritis and Rheumatism, 1972, 15, 617.

14 Nasu, T, Pathologia et Microbiologia, 1975, 43, 140.

15 Danaraj, T J, Wong, H O, and Thomas, M A, British Heart fournal, 1963, 25, 153.

16 Lande, A, American fournal of Roentgenology, 1976, 127, 227.

17 Lande, A, et al, New York State fournal of Medicine, 1976, 76, 1477.

${ }^{18}$ Kinare, S G, Pathologia et Microbiologia, 1975, 43, 134

19 Alpert, H J, Medical Annals of the District of Columbia, 1974, 43, 69.

20 De Bakey, M E, et al, fournal of the American Medical Association, 1958, 166, 998 .

${ }^{21}$ Aldasoro, G E, et al, International Surgery, 1976, 61, 168.

\section{Fungal infection of the eye}

A recent account from the Enugu Teaching Hospital, Nigeria, ${ }^{1}$ of fungal corneal ulcers has focused attention on a subject that Professor Barrie Jones ${ }^{2}$ has been studying for the last 10 years at the Institute of Ophthalmology in London. His interest was sparked off in a dramatic way when a woman was flown from Singapore after her corneal graft had become infected with a fungus. In spite of every effort an enucleation was eventually necessary. Since then research has led to considerable advances in treatment so that with early recognition good results are possible.

Despite widespread distribution in the atmosphere and on plant life, fungi do not normally cause eye infections. If, however, the resistance of the host has been lowered by illness or immunosuppression with steroids infection may develop. There has been an enormous increase in reported cases of fungal eye infection in the last 10 years, and as many as 100 different fungi have been incriminated. The clinical ${ }^{3}$ presentation is usually in the form of an indolent ulcer. Its surface is whitish yellow with raised edges and fingerlike processes extending into the stroma; there may be satellite lesions and pus in the anterior chamber (hypopyon). The appearances are very variable, with widely different pictures from different organisms. The diagnosis may and indeed should be confirmed by corneal scrapings, examined both histologically and by incubation. If after several scrapings there is no clear answer then an aqueous specimen or a corneal biopsy or both should be taken. Diagnosis must be accurate so that the right chemotherapeutic agent may be used. Untreated, the inevitable course of such an ulcer is to worsen, leading to haemorrhage 